
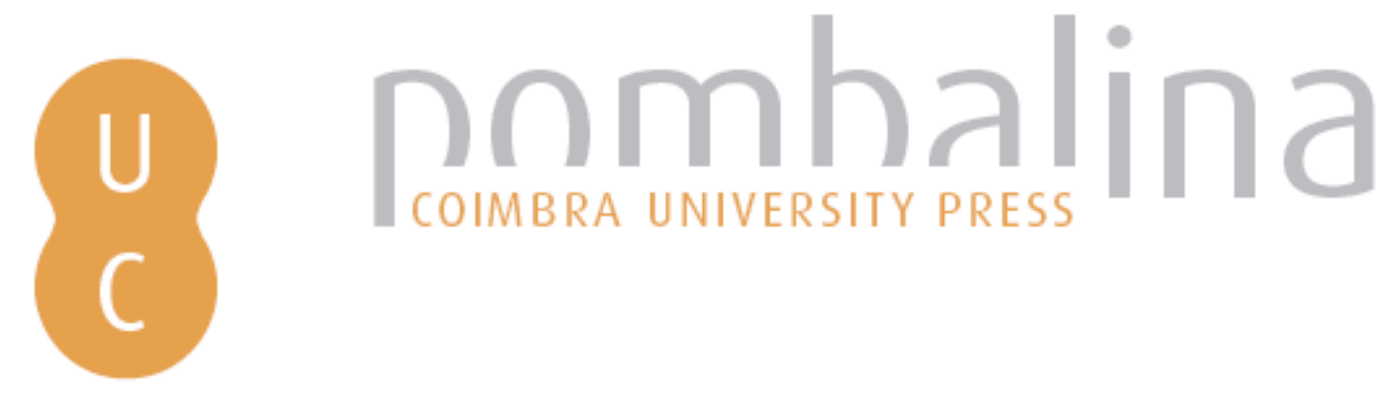

\title{
Contos de uma ciência periférica: Back, With a Vengeance
}

\author{
Autor(es): $\quad$ Carmo, André; Aurindo, Maria José
}

Publicado por: Imprensa da Universidade de Coimbra

URL

persistente: URI:http://hdl.handle.net/10316.2/30753

DOI: $\quad$ DOI:http://dx.doi.org/10.14195/978-989-26-0244-8_2

Accessed : $\quad$ 26-Apr-2023 11:16:34

A navegação consulta e descarregamento dos títulos inseridos nas Bibliotecas Digitais UC Digitalis, UC Pombalina e UC Impactum, pressupõem a aceitação plena e sem reservas dos Termos e Condições de Uso destas Bibliotecas Digitais, disponíveis em https://digitalis.uc.pt/pt-pt/termos.

Conforme exposto nos referidos Termos e Condições de Uso, o descarregamento de títulos de acesso restrito requer uma licença válida de autorização devendo o utilizador aceder ao(s) documento(s) a partir de um endereço de IP da instituição detentora da supramencionada licença.

Ao utilizador é apenas permitido o descarregamento para uso pessoal, pelo que o emprego do(s) título(s) descarregado(s) para outro fim, designadamente comercial, carece de autorização do respetivo autor ou editor da obra.

Na medida em que todas as obras da UC Digitalis se encontram protegidas pelo Código do Direito de Autor e Direitos Conexos e demais legislação aplicável, toda a cópia, parcial ou total, deste documento, nos casos em que é legalmente admitida, deverá conter ou fazer-se acompanhar por este aviso. 


\section{TRUNFOS DE UMA}

\section{EOGRAFIA ACIVA}

\section{DESENVOLVIMENTO LOCAL,}

AMBIENTE,

ORDENAMENTO

E TECNOLOGIA

Norberto Santos

Lúcio Cunha

COORDENAÇÃO 
André Carmo, Maria José Aurindo

Geógrafos, IGOT - Universidade de Lisboa

\section{CONTOS DE UMA CIÊNCIA PERIFÉRICA: BACK, WITH A VENGEANCE ${ }^{1}$}

\section{UNIVERSIDADE E CRISE INSTITUCIONAL}

A Universidade é uma instituição de grande complexidade, possuidora de um metabolismo próprio, isto é, de um conjunto de agentes inter-relacionados responsáveis pelo seu funcionamento, evolução e sobrevivência. Barata-Moura (1999) considerou-a «uma instituição social de nível superior, destinada ao cultivo dos saberes num processo de formação de humanidade». Esta definição engloba dois aspectos decisivos para um entendimento holístico desta instituição, nomeadamente, a sua natureza social, no duplo sentido de espaço de aculturação e socialização, e o seu carácter dinâmico, decorrente do entendimento processual associado à formação universitária.

Neste contexto, a Universidade pode ser entendida como uma instituição social que tem como funçóes a produção (investigação), reprodução (ensino) e disseminação de conhecimento, e é marcada por uma tensão constante entre duas forças antagónicas (cuja origem pode ser endógena ou exógena), imobilismo (i.e. paralisia) e dinamismo (i.e. mudança).

Há cerca de 15 anos, Santos (1994) identificou três crises interligadas que, no seu entender, iriam marcar as décadas seguintes da Universidade Portuguesa: i) hegemonia; ii) legitimidade; iii) institucional.

Hoje, é esta última que tem monopolizado os debates em torno do presente e do futuro da Universidade. Nesse sentido, considera-se que duas transformaçóes actualmente em curso podem, de certa forma, ser vistas como espelhando algumas das tensóes geradas pela crise institucional: i) Processo de Bolonha (ver Salgueiro, 2005); ii) Regime Jurídico das Instituiçóes de Ensino Superior (RJIES).

Esta breve caracterização institucional da Universidade e das dinâmicas que lhe estão associadas é importante e deve servir de fio condutor para a análise que se segue, na medida em que a Geografia Universitária Portuguesa não deve ser entendida fora dos contextos particulares em que se manifesta. Estes estabelecem os limites dentro dos quais os diferentes departamentos e centros de investigação podem delinear as suas estratégias.

\footnotetext{
${ }^{1}$ Agradece-se a colaboração prestada pelos professores Lúcio Cunha (Departamento de Geografia da Universidade de Coimbra), João Seixas (Instituto de Ciências Sociais da Universidade de Lisboa) e António Antunes Martins (Departamento de Geociências da Universidade de Évora).
} 


\section{A Geografia NA Universidade Portuguesa}

Actualmente, existem sete instituiçóes de ensino superior onde a formação em Geografia está presente (seis públicas e uma privada ${ }^{2}$. Com excepção da ECT-EU, onde não é ministrado o $2^{\circ}$ ciclo/mestrado, todas oferecem formação ao nível do $1^{\circ}$ ciclo/licenciatura e do $2^{\circ}$ ciclo/mestrado. O $3^{\circ}$ ciclo/doutoramento encontra-se apenas disponível no IGOT-UL, na FCSH-UNL, na FLUC e na FLUP.

Relativamente ao $1^{\circ}$ ciclo/licenciatura, nas últimas duas décadas a maior parte das instituiçôes existentes procedeu a reformulaçóes mais ou menos profundas ao nível da sua organização. São particularmente relevantes as tendências para uma cada vez maior especialização e diversificação da oferta formativa. Estas mudanças procuram dar resposta às exigências do mercado. Sintomático desta necessidade foi o acentuar da existência de alternativas profissionalizantes, que não o ensino ou a investigação, e a aposta numa maior instrumentalização. A este respeito, Lúcio $\mathrm{Cunha}^{3}$ assinala que a última década ficou marcada pela introduçáo de disciplinas de cariz mais prático, como por exemplo, as ligadas aos SIG e pela diminuição do investimento e da procura nas áreas ligadas ao ensino.

Ao nível do $2^{\circ}$ ciclo/mestrado, a oferta é bastante diversificada, aprofundando o «esforço de especialização na preparação do capital humano», identificado por Malheiros (1999: 118). Com excepção do ICS-UM e da ECT-UE, todos as outras instituiçóes oferecem pelo menos três áreas/domínios de especialização. Salienta-se, mais uma vez, a importância dos SIG (apenas duas instituiçôes não oferecem uma especialização nesta área/domínio). Paralelamente, a gestão, o ordenamento e o desenvolvimento do território são também áreas/domínios privilegiadas ao nível da oferta existente a este nível.

Finalmente, ao nível do $3^{\circ}$ ciclo/doutoramento, ministrado pelos IGOT-UL, FCSH-UNL, FLUC e FLUP, existe ainda uma grande heterogeneidade, pois a grande diversidade de áreas/domínios cobertos pelas primeiras duas instituiçóes contrasta com uma oferta mais escassa no caso das últimas. A FLUC oferece formação de $3^{\circ}$ ciclo em Geografia nos ramos de Geografia Física e Humana enquanto a FLUP não diferencia nenhuma área/domínio.

Salienta-se também, na perspectiva da formaçáo contínua e ao longo da vida, o facto de algumas instituiçôes (ex: FCSH-UNL, IGOT-UL) terem começado a ministrar recentemente cursos de curta duração vocacionados para um público mais vasto. Parece-nos ser uma das áreas em que a escassez e a irregularidade da oferta são um dos obstáculos mais fortes à sua verdadeira consolidação.

Hoje, existem quatro centros/unidades de investigação em Geografia ${ }^{4}$. A leitura dos últimos relatórios de avaliaçáo disponibilizados pela Fundação para a Ciência e a Tecnologia

2 O recentemente criado Instituto de Geografia e Ordenamento do Território da Universidade de Lisboa (IGOT-UL), que integra o Departamento de Geografia da Faculdade de Letras da Universidade de Lisboa (FLUL) e o Centro de Estudos Geográficos da Fundação da Universidade de Lisboa (CEG-UL), a Faculdade de Ciências Sociais e Humanas da Universidade Nova de Lisboa (FCSH-UNL), a Faculdade de Letras da Universidade de Coimbra (FLUC), a sua homóloga do Porto (FLUP), o Instituto de Ciências Sociais da Universidade do Minho (ICS-UM), a Escola de Ciências e Tecnologia da Universidade de Évora (ECT-UE) e a Faculdade de Arquitectura, Urbanismo, Geografia e Artes da Universidade Lusófona (FAUGA-UL).

${ }^{3}$ Entrevista, Setembro de 2009 .

${ }^{4}$ Centro de Estudos Geográficos da Universidade de Lisboa (CEG-UL), o Centro de Estudos de Geografia e Ordenamento do Território (CEGOT), o Centro de Estudos de Geografia e Planeamento Regional (e-GEO) e a Unidade de Estudos e Investigação de Ciências Sociais Aplicadas (UEICSA), sediada na FAUGA-UL. 
(FCT), referentes ao ano de 2007, permite-nos sublinhar os seguintes aspectos: i) qualidade geral é elevada; ii) maior número de investigadores encontra-se no e-GEO (76), seguido do CEG-UL (74), do CEGOT (55) e da UEICSA (39); iii) grande heterogeneidade ao nível das áreas/domínios de investigação. Não obstante, a investigação em torno de questôes ambientais, urbanas, planeamento territorial/espacial, turismo e SIG é comum à maior parte dos centros/unidades.

Finalmente, devem referir-se dois aspectos negativos associados ao funcionamento dos centros/unidades analisados: i) acentuada endogamia dos investigadores; ii) grande irregularidade das publicaçóes científicas neles produzidas.

\section{UNIVERSIDADE, GEÓGRAFOS E MERCADO DE TRABALHO}

A Geografia, no segmento de trabalho associado ao seu ensino (até ao nível do Ensino Superior), tem vindo a assistir a um decréscimo da sua importância relativa no mercado de emprego. Tendência que já era notada por Malheiros, mas que é agora mais evidente com a extinção das formaçóes ao nível do $1^{\circ}$ ciclo/licenciaturas associadas ao ensino.

Por sua vez, as universidades, que já começaram a ver sinais da diminuiçáo da procura dos seus cursos, começam a apostar nos cursos de $2^{\circ}$ e $3^{\circ}$ ciclo, geralmente mais direccionados para os profissionais da área ligados à investigação ou à prestação de serviços, mas menos para o ensino da Geografia.

Apesar da procura dos cursos de $2^{\circ}$ e $3^{\circ}$ ciclo estar abaixo das expectativas, a procura/ /necessidade de formação e actualização de conhecimentos por parte de ambas as categorias profissionais mencionadas anteriormente é bastante significativa (embora mais fácil de constatar no domínio do ensino com as actividades desenvolvidas, por exemplo, pela Associação Portuguesa de Professores de Geografia (APGeo)).

Estas procuram suprir diferentes necessidades, que vão desde a mera acumulação de créditos, à procura de actualização da formação para um melhor desempenho profissional, passando pela necessidade de dominar novas técnicas ou instrumentos que se tenham entretanto tornado necessários no desempenho das suas funçóes. Parece-nos que a necessidade desta formação de carácter menos académico existe e é importante que seja suprida para que se continue a promover a utilidade social da geografia e o papel dos geógrafos no desenvolvimento. Talvez seja altura do Ensino Superior aumentar e diversificar este tipo de oferta formativa, adaptando-se às novas procuras ou, se este náo o fizer, que existam instituiçôes que o consigam fazer.

Relativamente à articulação entre os diferentes níveis de ensino, mais de uma década volvida, o traçado de convergência que Malheiros procurava que náo fosse interrompido em benefício de «ambos os mundos» poderá não tê-lo sido, mas parece estagnado.

Quando pensamos no associativismo verificamos uma separaçáo entre a APGeo e a Associação Portuguesa de Geógrafos (APG). Teremos massa crítica suficiente para manter estas duas associaçóes profissionais? Não seria mais profícuo unir esforços? Não teremos aqui, mais uma vez, "velhas imagens mitificadas», mas alargadas também ao mundo dos profissionais técnicos que muitas vezes referem não procurar a $\mathrm{APG}$ por não responder às necessidades que sentem de aproximação à comunidade e actualização de conhecimentos?

Se para o ensino da Geografia no domínio da empregabilidade a tendência foi claramente descendente, nos «outros caminhos do geógrafo» a situação foi a contrária: este tem 
vindo a ocupar cada vez mais lugares em Câmaras Municipais, Associações de Desenvolvimento Regional, ONGs, e participado na elaboração de Estudos e Planos vários. Também no sector privado, em empresas associadas ao planeamento, urbanismo, arquitectura, engenharia, entre outras, tem estado envolvido. Na verdade, como indica Lúcio Cunha, «o facto de termos hoje dois geógrafos como Secretários de Estado no Governo é o corolário do bom trabalho que tem vindo a ser realizado por dezenas e dezenas de geógrafos».

Porém, como destaca João Seixas ${ }^{5}$, os geógrafos não parecem ter ainda «um papel relevante no planeamento do território", até porque este continua a ser uma figura de segunda instância na política e na administração portuguesa. Ou seja, a (ir)relevância do trabalho dos geógrafos é influenciada por circunstâncias outras que não a qualidade da sua formação e do trabalho que desenvolvem.

Em suma, o investimento/procura nas áreas associadas ao ensino da Geografia tem sofrido um decréscimo assinalável enquanto noutras áreas/domínios tem crescido de forma sistemática e consistente.

\section{A CIÊNCIA GEOGRÁFICA PORTUGUESA}

Para além das implicações em termos de investigação, a ruptura verificada entre Geografia Física e Humana iniciada na década de 70, significou também que a «a imagem do geógrafo como integrador de diferentes saberes colocado num quadro científico que combinava matérias das ciências naturais e sociais foi-se progressivamente erodindo» (Malheiros, 1999: 122).

$\mathrm{Na}$ verdade, se no conjunto dos artigos publicados nas revistas de Geografia analisadas, ${ }^{6}$ a relação entre a produção de Geografia Humana e a Geografia Física registou um decréscimo muito pouco acentuado, quando consideramos as comunicaçóes apresentadas nos vários Congressos é notória uma grande irregularidade (Quadro 1).

Em 2007 observa-se o menor valor de que há registo, significando que a Geografia Física se encontra numa posição de menor subalternização face à Geografia Humana. Para além disso, a valorização das temáticas de convergência continua a aumentar, pois apesar do ambiente continuar a ser o tema integrador por excelência, as questóes relacionadas com o ensino (educação geográfica, educação ambiental, educação para a cidadania), o planeamento e o ordenamento têm vindo a ganhar um cada vez maior relevo.

Salienta-se também o crescimento que a cartografia e os SIG têm vindo a sofrer, patente no aumento consistente de comunicaçóes nesta área, não só enquanto temática de investigação por direito próprio mas também enquanto ferramenta de análise e descrição frequentemente utilizada na Geografia Física.

\footnotetext{
${ }^{5}$ Entrevista, Setembro de 2009.

${ }^{6}$ Para além da referência aos artigos e comunicações analisados por Malheiros (1999), foram analisados os últimos quatro volumes das revistas Cadernos de Geografia ( $\mathrm{No}_{s}$ 19, 20, 21/23 e 24/25), Finisterra ( $\mathrm{No}_{s}$ 82, 83, 84 e 86) e Inforgeo ( $\mathrm{N}^{\circ}$ s $15,16 / 17,18 / 19$ e 20/21). No caso da Finisterra, optou-se por náo incluir o no 85 por se tratar dum número especial. Para além destas foram analisadas as revistas Análise Social ( $\mathrm{N}^{\circ} \mathrm{s}$ 186, 187, 188 e 189) e Sociedade e Território ( $\mathrm{N}^{\circ}$ s 37/38, 39, 40 e 41). Para além destas publicaçóes, foram também usadas as listas de comunicaçóes referentes aos dois primeiros Congressos da Geografia Portuguesa (analisadas por Malheiros) bem como as comunicaçóes referentes aos $4^{\circ}, 5^{\circ}$ e $6^{\circ}$ Congressos, cujo tratamento é da nossa autoria. Tal como no artigo original, sublinha-se o carácter exploratório deste ensaio pelo que um tratamento mais exaustivo e sistemático continua a ser necessário.
} 
Quadro 1 - Relaçẫo entre artigos e comunicaçôes de Geografia Física e Humana em revistas desta área científica e nos Congressos da Geografia Portuguesa

\begin{tabular}{|c|c|c|c|c|c|}
\cline { 2 - 6 } \multicolumn{1}{c|}{} & Física & Humana & $\begin{array}{c}\text { Cartografia \& } \\
\text { SIG }\end{array}$ & $\begin{array}{c}\text { Convergência } \\
\text { Disciplinar }\end{array}$ & Humana/Física \\
\hline Artigos (1992/96) & 17 & 42 & - & - & 2,5 \\
\hline Artigos $(2000 / 08)$ & 30 & 72 & 5 & - & 2,4 \\
\hline $\begin{array}{c}1^{\circ} \text { Congresso }- \\
1991\end{array}$ & 2 & 21 & - & - & 14,5 \\
\hline $\begin{array}{c}2^{\circ} \text { Congresso } \\
1994\end{array}$ & 6 & 33 & - & 6 & 5,5 \\
\hline $\begin{array}{c}4^{\circ} \text { Congresso } \\
2001\end{array}$ & 2 & 26 & 8 & 10 & 11 \\
\hline $\begin{array}{c}5^{\circ} \text { Congresso - } \\
2004\end{array}$ & 6 & 67 & 26 & 17 & 4,5 \\
\hline $\begin{array}{c}6^{\circ} \text { Congresso - } \\
2007\end{array}$ & 17 & 76 & 13 & & \\
\hline
\end{tabular}

A resposta dada pela Geografia à crescente ameaça colocada por outras disciplinas, apesar de tardia, avançou no sentido do reforço da convergência disciplinar, minimizando também a posiçáo desvantajosa anteriormente ocupada pela Geografia Física. $\mathrm{Na}$ verdade, tal como refere António Martins ${ }^{7}$, o ambiente, o planeamento e o ordenamento têm-se vindo a tornar domínios cada vez mais importantes para os centros/unidades de investigação atrás analisados.

$\mathrm{Na}$ actualidade, a Geografia Portuguesa continua a não manifestar um reforço substancial da interdisciplinaridade, ou seja, apesar de se verificar um aumento da produção conjunta por parte de geógrafos e não geógrafos, esta ainda é bastante incipiente (Quadro 2). Observa-se também uma diminuição da percentagem de artigos produzidos por investigadores oriundos de outras áreas científicas. Isto poderá indiciar uma tendência para o progressivo encerramento da disciplina sobre si própria, fechando a porta a contributos que lhe seriam obviamente benéficos.

Destaca-se também o facto da colaboração entre geógrafos portugueses de universidade diferentes ter sofrido um aumento substancial (Quadro 2), que se deve, sobretudo, à colaboração sistemática e já consolidada de investigadores do CEG-UL e do e-GEO na área/domínio dos SIG.

Quadro 2 - Resumo da análise dos artigos produzidos nas revistas de Geografia

\begin{tabular}{|l|c|c|c|c|}
\cline { 2 - 5 } \multicolumn{1}{l|}{} & $2000 / 08$ & $\%$ & $1992 / 96$ & $\%$ \\
\hline No total de artigos & 121 & 100,0 & 84 & 100 \\
\hline Artigos nacionais & 97 & 80,2 & 63 & 75 \\
\hline Artigos estrangeiros & 24 & 19,8 & 21 & 25 \\
\hline Artigos produzidos conjuntamente por geógrafos e não geógrafos & 3 & 2,5 & 1 & 1,2 \\
\hline $\begin{array}{l}\text { Artigos produzidos por geógrafos portugueses de universidades } \\
\text { diferentes }\end{array}$ & 11 & 9,1 & 4 & 4,8 \\
\hline Artigos conjuntos entre estrangeiros e portugueses & 3 & 2,5 & 1 & 1,2 \\
\hline Artigos produzidos por investigadores de outras áreas científicas & 8 & 6,6 & 7 & 8,3 \\
\hline
\end{tabular}

\footnotetext{
${ }^{7}$ Entrevista, Setembro de 2009.
} 
Para além disso, a Geografia continua a manifestar algum fechamento face à comunidade científica internacional. Por um lado, o aumento da produção feita em colaboração com geógrafos estrangeiros é muito reduzido, por outro, a publicação de autores estrangeiros nas revistas de geografia portuguesa analisadas sofreu um significativo decréscimo face ao período analisado por Malheiros (Quadro 2).

Como tínhamos referido, apesar dos dados anteriores indicarem um ligeiro fechamento disciplinar, quando analisamos a produção bibliográfica das revistas de Geografia é notória a maior abertura, pois são cada vez mais feitas referências a não geógrafos (Quadro 3). O que é mais surpreendente, embora não inesperado, e reforçando o argumento inicial apresentado por Malheiros, é o facto da Geografia Humana necessitar cada vez mais de recorrer ao conhecimento produzido por não geógrafos. Em contraposição, a Geografia Física, apesar de relativamente mais aberta, continua ainda bastante fundada na produção científica que é feita por geógrafos nacionais.

Quadro 3 - Relação entre a bibliografia de geógrafos (RG) e não geógrafos nacionais (RNG) citada nos artigos escritos por portugueses nas revistas de Geografia

\begin{tabular}{|l|c|c|c|c|c|c|}
\cline { 2 - 7 } \multicolumn{1}{c|}{} & \multicolumn{2}{c|}{ RG } & \multicolumn{2}{c|}{ RNG } & \multicolumn{2}{c|}{ Relaçáo RG/RNG } \\
\cline { 2 - 7 } \multicolumn{1}{c|}{} & $1992 / 96$ & $2000 / 08$ & $1992 / 96$ & $2000 / 08$ & $1992 / 96$ & $2000 / 08$ \\
\hline Física & 60 & 136 & 19 & 46 & 3,2 & 3,0 \\
\hline Humana & 144 & 393 & 97 & 494 & 1,5 & 0,8 \\
\hline Total & 204 & 529 & 116 & 530 & 1,8 & 1,0 \\
\hline
\end{tabular}

Ao nível da incapacidade da Geografia para exportar a sua produção científica para outras áreas disciplinares, a tendência manteve-se. Não deixa de ser preocupante que numa revista «caracterizada por uma abertura disciplinar no âmbito das ciências sociais e por preocupações ao nível da reflexão teórica e da investigação aplicada em diferentes áreas» (Malheiros, 1999: 125), nenhum dos artigos da revista Análise Social analisados tenha sido produzido por geógrafos. Continuam assim a fazer-se sentir os dois aspectos referidos por Malheiros. Por um lado, o anteriormente referido autocentramento da Geografia e, por outro, o facto de os geógrafos continuarem a assumir uma atitude científica excessivamente empiricista, não se mostrando muito disponíveis para participar em investigaçóes não imediatamente aplicáveis e discussóes de carácter eminentemente teórico.

Paralelamente, quando analisamos uma revista mais vocacionada para as questóes do planeamento territorial, sistemas urbanos e cidades, logo mais próximo da orientação científica seguida pelos geógrafos portugueses, observa-se uma maior presença de geógrafos, pois cerca de $15 \%$ dos 45 artigos analisados foram por eles produzidos.

No que diz respeito à internacionalização, destaca-se o aumento na ordem dos 200\% do número de referências bibliográficas contabilizadas em artigos escritos por autores estrangeiros nas revistas de Geografia. Este acréscimo é superior na área da Geografia Humana, sendo que na área da Geografia Física o crescimento foi bastante menor (cerca de $60 \%$ ) no que diz respeito às referências a autores nacionais (Quadro 4). 
A projecção internacional da Geografia continua a ocorrer sobretudo ao nível do espaço europeu, existindo uma presença crescente de equipas portuguesas em projectos, congressos e outras actividades europeias.

Infelizmente, persistem os constrangimentos associados ao desenvolvimento de uma Geografia Lusófona. As relaçóes com os PALOP continuam a manifestar alguma inconsistência bem como aquelas estabelecidas com instituiçóes brasileiras.

Quadro 4 - Relação entre as referências bibliográficas nacionais (RN) e estrangeiras (RE) que constam nos artigos escritos por portugueses nas revistas de Geografia -

$1992 / 1996$ e $2000 / 2008$

\begin{tabular}{|c|c|c|c|c|}
\cline { 3 - 5 } \multicolumn{2}{c|}{} & RE & RN & $\begin{array}{c}\text { Relação } \\
\text { RN/RE }\end{array}$ \\
\hline \multirow{2}{*}{ Área de Física } & $1992 / 1996$ & 115 & 79 & 0,69 \\
\cline { 2 - 5 } & $2000 / 2008$ & 431 & 128 & 0,3 \\
\hline $\begin{array}{c}\text { Área de } \\
\text { Humana }\end{array}$ & $1992 / 1996$ & 432 & 241 & 0,56 \\
\cline { 2 - 5 } & $2000 / 2008$ & 1627 & 763 & 0,47 \\
\hline \multirow{2}{*}{\begin{tabular}{c} 
Total \\
\cline { 3 - 5 }
\end{tabular}} & $1992 / 1996$ & 547 & 320 & 0,59 \\
\cline { 2 - 5 } & $2000 / 2008$ & 2202 & 891 & 0,4 \\
\hline
\end{tabular}

Se é importante compreendermos as nossas relaçóes com o exterior (outras ciências, e ao nível internacional) é essencial não esquecer a relevância das relações internas. Se observarmos o quadro 5 conseguimos perceber rapidamente que se mantém o que Malheiros (1999: 126) qualificou de "posicionamento fragmentário e localista, com um certo imperialismo lisboeta e uma tendência para um bairrismo não comprovado por parte do Porto».

Quadro 5 - Proporção de referências bibliográficas a geógrafos que trabalham no mesmo local relativamente ao total de referências a geógrafos nacionais nas revistas de Geografia - 1992/1996 e $2000 / 2008$

\begin{tabular}{|l|c|c|}
\cline { 3 - 3 } \multicolumn{2}{|c|}{} & $\%$ \\
\hline \multirow{2}{*}{ Artigos de Geógrafos de Lisboa } & $1992 / 1996$ & 92 \\
\cline { 2 - 3 } & $2000 / 2008$ & 89 \\
\hline Artigos de Geógrafos de Coimbra & $1992 / 1996$ & 59 \\
\cline { 2 - 3 } & $2000 / 2008$ & 71 \\
\hline \multirow{2}{*}{$\begin{array}{l}\text { Artigos de Geógrafos do Porto } \\
\text { Artigos produzidos por Geógrafos com actividades } \\
\text { noutros locais }\end{array}$} & $1992 / 1996$ & $100^{*}$ \\
\cline { 2 - 3 } & $2000 / 2008$ & $83^{* *}$ \\
\cline { 2 - 3 } & $2000 / 2008$ & 57 \\
\hline
\end{tabular}

Constata-se assim que o "Arquipélago Geográfico Português» continua a ser marcado por uma relativa desarticulaçáo interna bem como pela incapacidade de, ao nível da investigação, transcender a escala europeia de forma coerente e sistemática. Pensamos que muito do sucesso da Geografia Portuguesa da próxima década passará pela capacidade de providenciar respostas adequadas a estes desafios. 


\section{MATRIZ de AVALIAÇÃO: CONTRASTES E CONTINUIDADES}

\begin{tabular}{|c|c|c|c|}
\hline Pontos Fortes & Pontos Fracos & Ameaças & Oportunidades \\
\hline \multicolumn{4}{|c|}{ Ensino Universitário } \\
\hline $\begin{array}{l}\text { - Formação de base } \\
\text { forte e consolidada } \\
\text { - Capacidade } \\
\text { científica dos docentes } \\
\text { - Crescente } \\
\text { especialização e } \\
\text { diversificaçáo da } \\
\text { oferta formativa } \\
\text {-Maior } \\
\text { internacionalização } \\
\text { dos estudantes e } \\
\text { docentes, com } \\
\text { particular relevância } \\
\text { para o espaço Europeu }\end{array}$ & $\begin{array}{l}\text { - Capacidade pedagógica dos } \\
\text { docentes } \\
\text { - Incapacidade para a implementação } \\
\text { consistente de estágios fora do ensino } \\
\text { - Diminuiçáo do } \\
\text { investimento/procura nas áreas } \\
\text { ligadas ao ensino da Geografia } \\
\text { - Adiamento da especialização dos } \\
\text { estudantes para o } 2^{\circ} \text { Ciclo } \\
\text { - Insuficiente promoçáo e } \\
\text { desenvolvimento da formação não } \\
\text { conducente a grau } \\
\text { - Deficiências na formação técnica } \\
\text { (sobretudo ao nível das metodologias } \\
\text { quantitativas) } \\
\text { - Fraca aposta no saber-fazer }\end{array}$ & $\begin{array}{l}\text { - Aumento da } \\
\text { concorrência de } \\
\text { novos cursos com } \\
\text { forte especialização } \\
\text { técnica e } \\
\text { vocacionados para a } \\
\text { intervençáo no } \\
\text { território (ex: } \\
\text { arquitectura, } \\
\text { urbanismo) } \\
\text { - Dificuldades } \\
\text { decorrentes de um } \\
\text { ensino convergente }\end{array}$ & $\begin{array}{l}\text { - Crescente relevância da } \\
\text { Cartografia \& SIG } \\
\text { - Adopção do processo } \\
\text { de Bolonha possibilita } \\
\text { uma maior mobilidade } \\
\text { dos estudantes } \\
\text { - Novos Curricula/ } \\
\text { Modelos/ Planos } \\
\text { curriculares fomentam a } \\
\text { preparaçáo do aluno, } \\
\text { orientando-o ao invés de } \\
\text { o formatar, de forma a } \\
\text { incrementar o seu } \\
\text { espírito crítico e a lidar } \\
\text { com a ambiguidade e a } \\
\text { incerteza }\end{array}$ \\
\hline \multicolumn{4}{|c|}{ Investigaçáo em Geografia } \\
\hline $\begin{array}{l}\text { - Qualidade dos } \\
\text { centros/unidades de } \\
\text { investigaçáo é elevada } \\
\text { - Bom nível de } \\
\text { internacionalização, } \\
\text { nomeadamente no } \\
\text { espaço Europeu } \\
\text { - Crescimento da } \\
\text { convergência } \\
\text { disciplinar } \\
\text { - Diversidade de } \\
\text { domínios temáticos } \\
\text { tratados face aos } \\
\text { recursos (humanos e } \\
\text { não só) disponíveis }\end{array}$ & $\begin{array}{l}\text { - Posicionamento semi-periférico no } \\
\text { contexto das ciências } \\
\text { - Relativa incapacidade de articulação } \\
\text { regional interna } \\
\text { - Estrangulamento nas vertentes de } \\
\text { internacionalização viradas para os } \\
\text { países lusófonos (e não só...) } \\
\text { - Irregularidade das publicaçôes } \\
\text { científicas produzidas } \\
\text { - Endogamia dos investigadores } \\
\text { - Reduzida interdisciplinaridade } \\
\text { - Excessivo empiricismo } \\
\text { - Níveis de produtividade, sua } \\
\text { qualidade e grau de } \\
\text { internacionalização } \\
\text { - Articulação tardia e deficitária entre } \\
\text { ensino e investigação }\end{array}$ & $\begin{array}{l}\text { - Risco de } \\
\text { substituição no } \\
\text { papel de charneira } \\
\text { que outrora coube à } \\
\text { Geografia } \\
\text { - Capacidade/ } \\
\text { vontade de } \\
\text { trabalhar em equipa } \\
\text { e de concretização } \\
\text { - Escassez de uma } \\
\text { visão global sobre o } \\
\text { que se pretende } \\
\text { para o futuro (de } \\
\text { preferência } \\
\text { mensurável) }\end{array}$ & $\begin{array}{l}\text { - «Spatial turn» nas } \\
\text { ciências e na sociedade } \\
\text { coloca o espaço } \\
\text { geográfico no centro das } \\
\text { atençóes } \\
\text { - Desordenamento do } \\
\text { território necessita de } \\
\text { soluçóes para as quais o } \\
\text { contributo científico da } \\
\text { Geografia é indispensável } \\
\text { - Abertura de canais de } \\
\text { contacto com os outros } \\
\text { países do espaço lusófono } \\
\text { - Ferramentas, meios e } \\
\text { ambientes que facilitam } \\
\text { produção e comunicação }\end{array}$ \\
\hline
\end{tabular}

\section{REFERÊNCIAS BIBLIOGRÁFICAS}

Barata-Moura, J. 1999, 'Pensar e fazer Universidade' [Online]. Disponível em http://cie.fc.ul.pt/seminarioscie/ /universidade/jbmoura.htm

Malheiros, J. 1999, 'Contos de uma ciência periférica: Inovação, internacionalização e indisciplina(ridade) na geografia portuguesa', Inforgeo, 12/13, pp. 117-130.

Salgueiro, T. B. 2005, 'A Geografia Universitária em Época de Benchmarking, Finisterra, XL, 79, pp. 137-150. Santos, B. S. 1994, Pela Mão de Alice. O Social e o Político na Pós-Modernidade, Afrontamento, Porto. 